\title{
New Insights into Monoclonal B-Cell Lymphocytosis
}

\author{
Christina Kalpadakis, ${ }^{1}$ Gerassimos A. Pangalis, ${ }^{2}$ Sotirios Sachanas, ${ }^{2}$ \\ Theodoros P. Vassilakopoulos, ${ }^{3}$ Stavroula Kyriakaki, ${ }^{1}$ Penelope Korkolopoulou, ${ }^{4}$ \\ Efstathios Koulieris, ${ }^{2}$ Maria Moschogiannis, ${ }^{2}$ Xanthi Yiakoumis, ${ }^{2}$ \\ Pantelis Tsirkinidis, ${ }^{2,5}$ Marie-Christine Kyrtsonis, ${ }^{6}$ Georgia Levidou, ${ }^{4}$ \\ Helen A. Papadaki, ${ }^{1}$ Panayiotis Panayiotidis, ${ }^{6}$ and Maria K. Angelopoulou ${ }^{3}$ \\ ${ }^{1}$ Department of Haematology, University Hospital, University of Crete, P.O. BOX 1352, 71110 Heraklion, Crete, Greece \\ ${ }^{2}$ Department of Haematology, Athens Medical Center-Psychikon Branch, 11525 Athens, Greece \\ ${ }^{3}$ Department of Haematology, University of Athens, Laikon General Hospital, 11527 Athens, Greece \\ ${ }^{4}$ Department of Pathology, University of Athens, 11527 Athens, Greece \\ ${ }^{5}$ Department of Haematology, 401 Military Hospital, 11525 Athens, Greece \\ ${ }^{6} 1$ st Department of Propedeutics, University of Athens, Laikon General Hospital, 11527 Athens, Greece
}

Correspondence should be addressed to Christina Kalpadakis; xkalpadaki@yahoo.gr

Received 17 April 2014; Accepted 21 July 2014; Published 11 September 2014

Academic Editor: Kazuyuki Shimizu

Copyright @ 2014 Christina Kalpadakis et al. This is an open access article distributed under the Creative Commons Attribution License, which permits unrestricted use, distribution, and reproduction in any medium, provided the original work is properly cited.

\begin{abstract}
Monoclonal B-cell lymphocytosis (MBL) is a premalignant condition characterized by the presence of less than $5000 / \mu \mathrm{L}$ circulating clonal B cells in otherwise healthy individuals. Three subcategories have been identified according to the immunophenotypic features: CLL-like, CD5(+) atypical, and CD5(-) MBL. CLL-like MBL is by far the most frequent and best studied category and further divided in low-count [LC] and high-count [HC] MBL, based on a cutoff value of 500/ $\mu$ L clonal B cells. LC-MBL typically remains stable and probably does not represent a truly premalignant condition, but rather an age-related immune senescence. On the other hand, HC-MBL is closely related to CLL-Rai0, bearing similar immunogenetic profile, and is associated with an annual risk of progression to CLL requiring therapy at a rate of $1.1 \%$. Currently there are no reproducible factors for evaluating the risk of progression to CLL. CD5(-) MBL is characterized by an immunophenotype consistent with marginal zone origin and displays many similarities with marginal zone lymphomas (MZL), mainly the splenic MZL. The cutoff value of 5000/ $\mu \mathrm{L}$ clonal B cells cannot probably be applied in CD5(-) MBL, requiring a new definition to describe those cases.
\end{abstract}

\section{Introduction}

Multiparameter flow cytometry analysis dramatically increased the sensitivity for detection of small B-cell clones in otherwise healthy individuals [1-7]. A variety of terms have entered the literature to designate this finding. In 2005 the International Familial CLL consortium summarized the literature, proposed certain diagnostic criteria to define this entity, and established the term "monoclonal B-cell lymphocytosis" (MBL) [8]. MBL is characterized by an asymptomatic monoclonal expansion of $<5.0 \times 10^{9} / 1$ circulating $\mathrm{B}$ cells in apparently healthy individuals without any other feature diagnostic of a B-lymphoproliferative disorder. MBL is classified into three groups according to the immunophenotype of the clonal population. The majority of MBL cases (75\%) have the immunophenotype of chronic lymphocytic leukemia (CD19(+), CD5(+), CD23(+), CD20 dim , and $\left.\operatorname{sg}^{\mathrm{dim}}\right)$ and are classified as typical CLL-like MBL, while the remaining MBL cases are classified as atypical CLL $(\mathrm{CD} 5(+)$ clonal population not meeting the criteria for typical CLL and not meeting the criteria for mantle cell lymphoma) and as CD5(-) non-CLL $\operatorname{MBL}[4,5,8]$.

\section{CLL-Like MBL}

2.1. Prevalence. The reported prevalence of $\mathrm{MBL}$ ranges widely from $<1 \%$ to more than $18 \%$, depending on the 
TABLE 1: Prevalence of CLL-type MBL in some of the larger reported series.

\begin{tabular}{|c|c|c|c|c|c|c|c|}
\hline $\begin{array}{l}\text { Population } \\
\text { studied }\end{array}$ & $\begin{array}{c}\text { Median age, } \\
\text { Y (range) }\end{array}$ & $n$ & $\begin{array}{l}\text { Number of } \\
\text { colours }\end{array}$ & $\begin{array}{l}\text { Events } \\
\times 10^{3}\end{array}$ & $\begin{array}{l}\text { All ages in } \\
\text { study, \% }\end{array}$ & $\begin{array}{c}\text { CLL-type } \\
\mathrm{MBL}>60 \mathrm{y} \\
\%\end{array}$ & $\begin{array}{c}\text { MBL } \\
\text { counts } \\
\text { (median) }\end{array}$ \\
\hline $\begin{array}{l}\text { US residential } \\
\text { population [9] }\end{array}$ & $\begin{array}{c}53 \\
(40-76)\end{array}$ & 1926 & 2 & N.R. & 0.6 & $>0.6$ & $88 / \mu \mathrm{L}$ \\
\hline $\begin{array}{l}\text { US blood } \\
\text { donors [10] }\end{array}$ & $\begin{array}{c}45 \\
(18-79)\end{array}$ & 5141 & 2 & N.R. & 0.14 & 0.9 & NR \\
\hline $\begin{array}{l}\text { UK hospital } \\
\text { outpatients [4] }\end{array}$ & $\begin{array}{c}57 \\
(40-90)\end{array}$ & 910 & 4 & 200 & 3.5 & 5.0 & $0.013 \times 10^{9}$ \\
\hline $\begin{array}{l}\text { Italy primary } \\
\text { care }[5]\end{array}$ & $\begin{array}{c}74 \\
(65-98)\end{array}$ & 500 & 4 & 200 & 5.5 & 5.5 & $\begin{array}{c}0.114 \times 10^{9} \\
(\text { mean })\end{array}$ \\
\hline $\begin{array}{l}\text { UK hospital } \\
\text { outpatients with } \\
\text { normal ALC [11] }\end{array}$ & $\begin{array}{c}74 \\
(62-80)\end{array}$ & 1520 & 4 & 200 & 5.1 & 5.1 & NR \\
\hline $\begin{array}{l}\text { UK hospital } \\
\text { outpatients with } \\
\text { lymphocytosis } \\
\text { [11] }\end{array}$ & $\begin{array}{c}71 \\
(39-99)\end{array}$ & 2228 & 4 & 200 & 13.9 & NR & $\mathrm{NR}^{\prime}$ \\
\hline $\begin{array}{l}\text { Italy residential } \\
\text { population [12] }\end{array}$ & $\begin{array}{c}55 \\
(18-102)\end{array}$ & 1725 & 5 & 500 & 5.2 & 8.9 & $0.034 \times 10^{9}$ \\
\hline $\begin{array}{l}\text { Spain primary } \\
\text { care [3] }\end{array}$ & $\begin{array}{c}62 \\
(40-97)\end{array}$ & 608 & 8 & 5000 & 14.3 & $>20$ & $0.17 \times 10^{9^{c}}$ \\
\hline $\begin{array}{l}\text { US blood } \\
\text { donors [13] }\end{array}$ & $\begin{array}{c}57 \\
(45-91)\end{array}$ & 2098 & 6 & 500 & 4.8 & $10.7^{*}$ & $0.01 \times 10^{9}(10 / \mu \mathrm{L})$ \\
\hline $\begin{array}{l}\text { 1st-degree } \\
\text { relatives of } \\
\text { sporadic CLL } \\
{[14]}\end{array}$ & $\begin{array}{c}62 \\
(18-84)\end{array}$ & 167 & 4 & 300 & 4.2 & 15.6 & NR \\
\hline $\begin{array}{l}\text { 1st-degree } \\
\text { relatives of } \\
\text { familial CLL [15] }\end{array}$ & NR & 33 & $2-3$ & NR & 18 & NR & NR \\
\hline $\begin{array}{l}\text { 1st-degree } \\
\text { relatives of } \\
\text { familial CLL } \\
{[16]}\end{array}$ & $\begin{array}{c}47 \\
(23-86)\end{array}$ & 59 & 4 & NR & 13.6 & $>20$ & $5 / \mu \mathrm{L}$ \\
\hline
\end{tabular}

NR: not reported.

sensitivity of flow cytometry and the populations tested (Table 1). The absence of standardized flow cytometry methods for $\mathrm{MBL}$ diagnosis complicates determination of the true prevalence. Early population studies indicated an MBL prevalence of $0.1 \%$ to $3 \%$ by screening for B-cell clones with $1-$ to 3 -color flow cytometric analysis $[9,10]$. Studies using 4 - to 5 -color protocols revealed a higher prevalence, ranging from $3 \%$ to more than $6 \%[4,5,12]$. In the most sensitive study published to date, Nieto et al. utilized the highest sensitivity flow cytometry approaches available with the use of 8-color staining panels and the analysis of 5 million $B$ cells per subject and identified an MBL prevalence of 14\% among 608 healthy adults aged more than 40 years [3]. So, as the sensitivity of flow cytometry increases by the use of multicolor techniques and the analysis of greater numbers of B cells per subject, the prevalence of MBL increases over time.

MBL prevalence also varies based on the studied population. In the general population studies $\mathrm{MBL}$ is detectable in approximately $4 \%$ to $5 \%$ of adults when typical flow cytometric techniques are used (4-color with a detection sensitivity of $1: 10000$ events) $[4,5,12]$. General trends across studies indicate a greater risk of $\mathrm{MBL}$ among those with increasing age and among men, similar to CLL [4-6]. In the Spanish study, a CLL-like MBL was detected in more than 1 in 5 individuals over 60 years old $[3,7]$. Furthermore, the same group, based on the analysis of 638 healthy adults ( $>44$ years old), investigated the association between the frequency of CLL-like MBL and the volume of sample analyzed. Based on this model, they suggested that the frequency of MBL cases would rise to $100 \%$ for subjects older than 70 years when more than $45 \mathrm{~mL}$ of peripheral blood was analyzed [7]. In a recent study in 2098 healthy blood donors with the use of 6color flow cytometry and the analysis of at least 500000 events yielded an overall prevalence of 7.1\% [13]. The prevalence was higher in men than in women and increased with age in both genders. There was $\sim 1.4$-fold increase for every 10 years in 
TABLE 2: Representative studies on the risk of progression of HC-MBL and suggested cutoff values of clonal B cells for predicting the risk of progression.

\begin{tabular}{|c|c|c|c|c|c|}
\hline STUDY & Pts $n$ & $\begin{array}{l}\text { MEDIAN } \\
\text { FUP } \\
\text { (years) }\end{array}$ & Range & $\begin{array}{l}\text { CLL/SLL } \\
\text { requiring } \\
\text { therapy }\end{array}$ & B-cell count cutoff value \\
\hline $\begin{array}{l}\text { Shim et al., } 2007 \\
\text { [9] }\end{array}$ & $\begin{array}{c}N=185 \\
\text { Clinical MBL }\end{array}$ & 6.7 & $0.2-11.8$ & $1.1 \%$ per year & $<1900 / \mu \mathrm{L}$ no progression \\
\hline $\begin{array}{l}\text { Shanafelt et al., } \\
2009 \text { [17] }\end{array}$ & $\begin{array}{c}N=459 \\
\mathrm{MBL}=190\end{array}$ & 1.5 & $0.3-7.9$ & $1.4 \%$ per year & $\begin{array}{c}<11000 / \mu \mathrm{L} \text { predict better } \\
\text { TFS and OS }\end{array}$ \\
\hline $\begin{array}{l}\text { Rossi et al., } 2009 \\
{[18]}\end{array}$ & $\begin{array}{c}N=123 \\
\text { Clinical MBL }\end{array}$ & 3.6 & NS & $\begin{array}{l}4 \% \text { per year for the } \\
\text { first } 7 \text { years and } \\
\text { then } 0 \%\end{array}$ & $\begin{array}{c}<1200 / \mu \mathrm{L} \text { low risk } \\
\text { progression }\end{array}$ \\
\hline $\begin{array}{l}\text { Scarfo et al., } 2012 \\
{[19]}\end{array}$ & $\begin{array}{c}N=184 \\
\text { Clinical MBL }\end{array}$ & 3.75 & $0-306$ & $1.5 \%$ & $\begin{array}{cc}10374 & 2.4 \text { versus } 8.5 \\
5000 & 1.5 \text { versus } 5.2\end{array}$ \\
\hline
\end{tabular}

the MBL prevalence among men, starting from $6.0 \%$ in the 45-64-year-old group and reaching $12.2 \%$ in the 65 -year or older group.

MBL is more common in first-degree relatives of patients with familial CLL, with a reported prevalence of $12 \%$ to $18 \%$ [14-16]. This elevated MBL risk is particularly evident in young adults aged 16 to 40 years with a 17 -fold relative risk, suggesting that there is an inherited abnormality that increases susceptibility to development of MBL at a much earlier age than the general population. In relatives of patients with sporadic CLL the overall prevalence has been reported in the range of $4 \%$, similar to that detected in the general population. However, in individuals aged more than 60 years from families with sporadic CLL, the MBL risk seems to be significantly increased (approximately 16\%) similar to that seen in relatives of familial CLL cases [14].

In outpatient series the prevalence of MBL is almost the same as in the general population as long as patients with normal blood counts are encountered $[4,5]$. However in one study on 2228 outpatients aged 39-99 years who were referred for investigation of lymphocytosis, the prevalence of MBL was much higher, in the range of $13.9 \%$ [11].

2.2. Classification of MBL into Low and High Count. In the general population studies the majority of MBL cases have very low numbers of clonal $B$ cells, typically in the range of $0.1-10 / \mu \mathrm{L}$, with a median number of clonal $\mathrm{B}$ cells $0.001 \times 10^{9} / \mathrm{L}[20]$. In contrast, MBL cases identified after investigation of absolute lymphocytosis typically have clonal B-cell counts above $450 / \mu \mathrm{L}$ while the median absolute clonal B-cells count is $2,939 / \mu \mathrm{L}[11,18]$.

Based on this heterogeneity of the size of the B cell clone, MBL is now subdivided into two categories: high-count MBL (also known as clinical MBL) and low-count MBL [20, 21]. A cutoff value of $0.5 \times 10^{9}$ clonal B cells/L has been proposed by the literature for discriminating LC-MBL and $\mathrm{HC}-\mathrm{MBL}$ $[20,21]$. This cutoff value seems to be of clinical relevance, since the majority of MBL cases carry either very low-count clones ( $<56$ clonal B cells $/ \mu \mathrm{L}$ ) or more than $1500 / \mu \mathrm{L}$ clonal B cells, with different risk of progression [20].
Of note, both low- and high-count MBL cases usually display multiclonality, in contrast to CLL in which multiclonality is much less common $[22,23]$.

2.3. Clinical or High-Count MBL. HC-MBL is closely related to CLL-Rai0, as it has been shown by several series [11, $18,20,21,24]$. Current data indicate CLL is more likely to develop in individuals with clinical MBL than in those with low-count MBL [20]. In the study by Rossi et al. $123 \mathrm{HC}$ MBL cases were compared to 154 CLL Rai stage 0 cases [18]. Demographics were similar. MBL cases were characterized by lower percentage of bone marrow infiltration, better preserved immune function, more favorable genetic profile, slower disease kinetics, and longer TFS compared to CLL0 , suggesting that $\mathrm{HC}-\mathrm{MBL}$ is a distinct entity. However, another study by Kern et al. compared $298 \mathrm{MBL}$ cases with 356 CLL patients with regard to biological characteristics and cytogenetics and suggested that these two entities largely overlap and represent closely related stages of the same disease that differ only in tumour mass and that the separation of MBL and CLL by a threshold of $5,000 / \mu \mathrm{L}$ clonal B cells cannot be reproduced by genetic aspects [25]. Studies including cases with clinical MBL have shown that the annual risk of progression to CLL requiring therapy is $1 \%$ to $2 \%$ (Table 2 ) $[11,17,26,27]$. In the Leeds study 185 CLL-like MBL cases were followed for a median of 80 months and $1.1 \%$ per year required treatment for disease progression [20]. Similar results were observed in the Mayo Clinic studies which reported on 302 CLL-like MBL cases and observed a 1.4\% annual risk of progression to CLL requiring therapy with a median followup time of 18 months [17]. In the Italian study, 123 clinical CLL-like MBL cases were monitored for a median of 43 months and it was observed that $4 \%$ per year required therapy in the first 7 years and decreased thereafter to $0 \%$ [18]. These studies also showed that the absolute B-cell count is the most important determinant of progression to CLL. However there is not any established cutoff point of B-ALC to predict the risk of progression to CLL (Table 2). In the Italian study, a BALC greater than $3.7 \times 10^{9} \mathrm{~B}$ cells/L predicted the highest risk of developing CLL or SLL, whereas a B-ALC at presentation below $1,200 / \mathrm{L}$ was the optimal cutoff point to predict a stable 
lymphocyte count [18]. In the UK study cutoff points were similar to the Italian one [20]. A B-ALC below 1,200/L and above $4,000 / \mathrm{L}$ was the optimal cutoff point for predicting a stable and a rising lymphocyte count, respectively [20]. A Mayo Clinic study by Shanafelt et al. included patients with MBL and Rai stage 0 CLL and observed that a threshold of $11,000 / \mathrm{L}$ B-ALC at diagnosis optimally predicted treatmentfree survival as well as overall survival [28]. A similar cutoff point of 10,000/L B-ALC has been reported by Molica et al. as well as by Scarfo et al. as a predictor for time to first therapy $[19,29,30]$. In the latter study, by using a cutoff level of $10,374 / \mu \mathrm{L}$ clonal B cells, the difference in terms of annual risk of progression became larger (2.4 versus $8.5 \%$ per year) compared with the difference based on the traditional cutoff level of $5,000 / \mu \mathrm{L}$ clonal B cells ( $1.1 \%$ versus $5.2 \%$ per year) [19].

The above data indicate that, by using a higher cutoff level of B-ALC instead of the currently used $(5,000 / \mu \mathrm{L})$ for discriminating MBL from CLL Rai stage 0 , it seems that it can better assess the risk of progression. However studies are ongoing investigating the best cutoff value for discriminating MBL into LC-MBL and HC-MBL, with distinct biological and clinical significance, as well as for discriminating HCMBL from CLL Rai 0. Given the fact that B-cell count is a continuous variable, it is rather impossible to establish any specific B-cell count threshold to precisely identify MBL cases with no risk of progression [19].

Assessing the B-cell count seems not to be enough to sharply demarcate the lowest and the highest risk categories. Biological parameters may be needed to best stratify patients [19]. Several factors have been assessed for predicting outcome of MBL, but with conflicting results. Biological factors that have been proposed include IGHV homology, CD38, CD49d, and ZAP-70 expression, and FISH karyotype [18, 20, 21, 28]. Cytogenetic parameters as well as mutation status seem to have the best prognostic power for predicting the risk for progression to CLL $[18,25]$.

Another important finding of these studies is that progression to CLL did not plateau over a long follow-up time, indicating that clinical MBL always progresses to CLL if given sufficient time [31]. However, only a small number of patients will actually experience disease progression due to the low progression rates per year and the age of subjects.

Besides the risk for progression to CLL requiring therapy, HC-MBL carries also a higher risk of serious infection than the general population. Based on the Mayo Clinic database, Moreira et al. reported that HC-MBL is at $\sim 3$-fold higher risk of hospitalization with infection compared with a control population and that this risk is fourfold greater than the risk for progression to CLL requiring therapy [32]. Interestingly, this increased susceptibility to infections was not associated with hypogammaglobulinemia.

2.4. Low-Count or Population Screening MBL. Low-count MBL can be detected only by applying highly sensitive flow cytometry techniques in otherwise healthy individuals. Data on the outcome of low-count MBL is limited. Fazi et al. reported on 76 patients with LC-MBL and observed that, after a median follow-up time of 34 months, $90 \%$ of the cases persisted over time in contrast to only $44.4 \%$ and $66.7 \%$ of atypical CLL and CD5(-) MBL, respectively [33]. Furthermore they reported that most of the LC-MBLs remained stable without progression to clinically overt disease, suggesting that the potential risk of progression into overt CLL is exceedingly rare and definitely less than that of clinical MBL. These findings confirm the hypothesis that the natural history of LC-MBL differs from that of HC-MBL and LC-MBL does not represent a true preleukemic condition, in contrast to HC-MBL. These results are in line with the molecular and biologic differences observed between the two subgroups of MBL $[12,34,35]$.

Since the prevalence of LC-MBL is much higher in the elderly population with a peak of $75 \%$ in persons above 90 years of age, it seems that LC-MBL may represent an epiphenomenon of immunosenescence, observed in the elderly $[33,34]$. In accordance with this hypothesis is the finding of increased clonal T-cell populations [33]. In more than one-half of the cases multiple T-cell clones were identified, compared with the general population suggesting a widespread deregulation of the immune system in MBL. Clonal expansions of $\mathrm{T}$ cells are frequently observed in elderly individuals [36]. Moreover, it has been shown that LC-MBL is associated with reduced numbers of normal B-cell subsets, mainly of immature and naïve B cells [37].

2.5. Bone Marrow Histopathology. Bone marrow examination is not required for the establishment of MBL diagnosis. Therefore there is limited data on bone marrow findings in MBL [38]. Our group has recently evaluated the histopathological and immunohistochemical findings of bone marrow biopsies (BMB) in a series of 48 cases (data unpublished). The median percentage of bone marrow infiltration was $28 \%$ (range, 5-85\%). The pattern of infiltration was interstitial or mixed (nodular and interstitial) in the majority of the cases, $88 \%$. There was no correlation between the extent of $\mathrm{BM}$ infiltration and the absolute number of peripheral blood monoclonal B cells.

2.6. Cytogenetic and Molecular Features of MBL. Significant progress has been made recently regarding the molecular and cytogenetic aspects of MBL. Reports of chromosomal abnormalities in CLL-type MBL indicate that both LCMBL and HC-MBL carry the same cytogenetic aberrations associated with good prognosis CLL $[3,11,17,18,25,35$, $39,40]$. The frequency of $13 q$ deletions, the most favourable cytogenetic subgroup in CLL, is similar to that observed in newly diagnosed CLL, since it has been detected in more than one-third of CLL-like MBL, in both subcategories (low and high count). Even in the Salamanca series, del13q was detected in $36 \%$ of the cases, whereas in the Italian series by Fazi et al. dell3q was evident in $43.8 \%$ of the LC-MBL cases $[3,33]$. This suggests that $13 \mathrm{q}$ deletion occurs early in the natural history of CLL-like MBL and is probably not associated with the disease progression [41]. A similar finding is seen for trisomy 12 which has been detected in $8-22 \%$ of cases among different series including both HC-MBL and LC-MBL [3, 11, 17, 25, 33, 35]. However deletions of 11q and $17 \mathrm{p}$, which are seen in CLL in association with a poor 
prognosis, are infrequent in $\mathrm{HC}-\mathrm{MBL}$ and LC-MBL $[3,11$, $17,25,33,35]$. Overall, LC-MBL shows a lower frequency of genetic alterations associated with CLL than HC-MBL and CLL. Furthermore, coexistence of $\geq 2$ cytogenetic alterations is less frequent in MBLs than in CLL [35].

LC-MBL and HC-MBL have similar somatic hypermutation status, since more than two-thirds of the cases carry somatically mutated IgHV genes $[12,25,35,39]$. In the study by Vardi et al. [34], unmutated IgHV genes were used in approximately $25 \%$ of LC- and HC-MBL cases, similarly with CLL-0, while CLL > 0 cases displayed unmutated IgHV genes in a significantly higher frequency ( $45 \%)$. Significant differences have been identified regarding the usage of IgHV genes as well as the Ig gene repertoire between LC-MBL and HC-MBL $[12,34,35]$. The IGHV gene repertoire of LC-MBL displays pronounced differences compared with HC-MBL and CLL-0, such as suppressed frequency of the IGHV1-69, IGHV4-34, and IGHV3-23 genes and overrepresentation of the IGHV4-59/61 genes $[12,34]$. The latter genes are found with increased frequency in elderly individuals, confirming the notion that LC-MBL may represent an aspect of the agerelated immune senescence [42]. In contrast to LC-MBL, the IGHV repertoire of $\mathrm{HC}-\mathrm{MBL}$ closely resembles that of mutated CLL, since the IGHV3-07, IGHV3-23, and IGHV434 genes are used in around half of the cases [12,34]. A recent study by Orfao's group based on 78 CLL-like MBL and 117 CLL clones showed that certain patterns of IGHV gene usage are associated with specific genetic alterations [35]. Based on these findings the authors identified three different groups: a group including mainly LC-MBL commonly expressing the VH3-23 gene with no or isolated good prognosis cytogenetic alterations, another group which mainly consisted of HCMBL and advanced-stage CLL with a common usage of the VH1-69 gene along with the presence of poor prognosis cytogenetic alterations, and a third group with intermediate features. Another important difference between LC-MBL and $\mathrm{HC}-\mathrm{MBL}$ is the finding that $\mathrm{BcR}$ stereotypy is exceedingly rare in $\mathrm{LC}-\mathrm{MBL}$, in contrast to $\mathrm{HC}-\mathrm{MBL}$ and CLL, in which $\mathrm{BcR}$ stereotypy is a distinctive feature being present in almost one-third of patients [34, 43].

All the above findings further support the notion that LCMBL does not represent a truly preleukemic condition, but more possibly a physiological process of age-related immune senescence, despite being clonal. HC-MBL, on the other hand, displays significant similarities with CLL-0 at both the clinical and the biological level $[18,25]$. In the largest series published today including 333 CLL-like MBLs, HC-MBL exhibited the same frequency of unmutated rearrangements ( 25\%) with CLL-0 [34]. Furthermore, both HC-MBL and CLL- 0 cases presented similar IGHV gene repertoire, which differed from that of LC-MBL and CLL $>0$. Another important observation from the aforementioned study is the presence of BcR stereotypy in the same frequency as in CLL$0(\sim 20 \%)$, further supporting the possibility that these two entities have common immunogenetic profile.

Most CLL-like MBL cases display an indolent and stable clinical course. However a small proportion of $\mathrm{HC}-\mathrm{MBL}$ cases will eventually progress to CLL. On the other hand, it has been shown that virtually all CLL are preceded by an MBL
[3]. Since only a minority of MBLs will actually progress to CLL requiring therapy, it is of significant importance to be able to discriminate at diagnosis these rare cases which will eventually progress into a malignant disorder. Understanding the key mechanisms involved in the expansion of the MBL clones may help in a better understanding of the natural history of the disease and to modify our strategies for correctly managing B-cell premalignant states. Given the fact that cytogenetic abnormalities are commonly detected even in LC-MBLs, there is a possibility that their role may be very limited or even nonexistent in the early phases of $\mathrm{MBL}$ development $[34,41]$. The underlying mechanisms responsible for the development and evolution of MBL into CLL are not known yet. It is of interest that LC-MBL remains stable despite the fact that the proliferative stimuli, such as persistent Ag-induced activation of the BCR, lead to the acquisition of genetic aberrations. On the contrary, in HCMBL there is probably a genetic predisposition leading to quick transit from the LC-MBL to the HC-MBL/CLL phase [34]. Autonomous genetic abnormalities (e.g., a single mutation) affecting the same or parallel critical signaling pathways may further support and amplify the initial clonal expansion [41]. Among these multiple pathophysiologic mechanisms for the progression of MBL to CLL, antigen stimulation seems to play a critical role. Evidence exists in the literature for a link between infections and increased risk to develop CLL $[44,45]$.

Next generation sequencing technologies have allowed the identification of several genomic alterations in CLL with prognostic significance, such as mutations of ATM, p53, NOTCH1, SF3B1, and BIRC3 genes that might represent new biomarkers of potential clinical relevance [46-48]. In MBL these secondary lesions are found in a significantly lower frequency $(0 \%-3 \%)$ than in CLL $[23,49,50]$. However a recent multicenter trial by the Gruppo Italiano Studio Linfomi reported a much higher prevalence of NOTCH 1 mutations in $100 \mathrm{MBL}$ cases (11\%) by using a highly sensitive method [51].

Recently it has been proposed that microRNAs (miRs) are involved in the transition from monoclonal B-cell lymphocytosis (MBL) to CLL [52]. In a study, Ferrajoli et al. tested miR15a/16-1 cluster, miR-21, and miR-155 expression in purified $B$ cells of normal individuals, individuals with MBL, and patients with CLL, found that miR-155 was overexpressed in $\mathrm{B}$ cells from individuals with MBL and even more so in B cells from patients with CLL, when compared with B cells from normal individuals, and supported the use of cellular and plasma levels of miR-155 as biomarkers for the risk of progression in individuals with MBL [53].

Several studies have shown the existence of multiclonality in a significant proportion of MBL cases (up to 20\%) [22]. A recent study showed that the B-cell receptor of B-cell clones from multiclonal cases presented a slightly higher degree of HCDR3 homology than B-cell clones from monoclonal cases, in association with unique hematological (e.g., lower B-lymphocyte counts) and cytogenetic (e.g., lower frequency of cytogenetically altered clones) features usually related to earlier stages of the disease. Based on these findings, the authors supported the antigen-driven nature of such 
multiclonal B-cell expansions, with potential involvement of multiple antigens/epitopes [54].

The conclusion from the above studies is that the progression of MBL to CLL probably involves multiple pathophysiologic mechanisms including critical gene mutations and microenvironmental stimulation along with a CLL-prone genetic background [41].

\section{Practical Aspects Of MBL Diagnosis: Unresolved Issues}

3.1. Establishment of Reproducible Prognostic Factors: Drawing the Line between $M B L$ and $C L L-O$. There is active ongoing research in the field of molecular pathogenesis and progression of MBL to CLL. Significant advances have been recorded so far in order to better understand the clinical aspects of this entity. Currently, it is still a matter of debate which are the best B-cell cutoff value and biological or cytogenetic factors for predicting the risk of progression. Further studies are required in order to determine factors with prognostic significance that would allow us to identify, early, MBL cases with high risk for progression to CLL requiring therapy. On the other hand, among CLL-0 cases, a significant proportion would not progress. Ideally, in the future the category of clinical MBL could be applied for all these cases (MBL and CLL-0) with no risk for progression (irrespectively of their MBL count) and stratify into the group of CLL-0 only those cases with a tendency to progress [41].

3.2. Staging Procedures. According to the guidelines for MBL evaluation at diagnosis, no imaging studies are required [8]. This raises concerns about the possibility that at least a proportion of cases classified as MBL could in fact represent small lymphocytic lymphoma [55] with a nodal burden not evident by physical examination (e.g., intra-abdominal lymphadenopathy). There is limited data evaluating this topic. In the series by Scarfo et al. the vast majority (155/165) of the HC-MBL cases imaging studies were negative, arguing against this hypothesis [19]. Further studies are required to clarify the role of imaging studies in non-CLL-like MBL.

3.3. MBL in Blood Donors. Several of the general population studies for the identification of MBL have been performed in blood donors $[10,13]$. Recently, Shim et al. report that MBL is a surprisingly common finding in healthy blood donors in the range of $7.1 \%$ [13]. This finding raises concerns regarding the potential risk of transfer of a premalignant condition to recipients of blood transfusion [56]. Given the fact that there is an increased risk for development of a B-cell malignancy, particularly in CLL, with blood transfusions [57], it is very important to clarify this issue. Since LC-MBL is not typically associated with a risk of progression, blood products from such donors are probably acceptable. The potential risk mainly involves blood donors with HC-MBL. So the question is whether donors with mild lymphocytosis should be screened for MBL. In order to answer this question further studies are required. Until then, the recommendation of Shim et al. for a conservative approach to blood transfusions is warranted [13].
3.4. MBL in Transplant Donors. The implications for allogeneic transplantation are significantly more complicated than blood donation, especially if the transplant is for a CLL patient. MBL prevalence is especially high in relatives of familial CLL cases reaching $18 \%$ in some studies [15]. Given this high incidence, it is probably reasonable to recommend that potential HLA-matched sibling donors for CLL patients be tested for the presence of MBL or early CLL [58]. Currently, there is limited data evaluating the risk of MBL transfer to recipients and the impact on overall survival after transplantation.

3.5. Ethical Considerations. Clinicians usually face difficulty on how to inform and follow up an individual with a diagnosis of MBL. The most sensible strategy, for the HC-MBL cases, is to reassure them that MBL is not a malignant entity and that the risk of progression to CLL is low, but not negligible, indicating a yearly hematologic consultation with a complete blood cell count and physical examination [31, 41]. For LC$\mathrm{MBL}$, which is identified in general population studies after the application of high-sensitivity flow cytometry methods, the risk of progression to CLL is very low, if any. Based on these data, it would be appropriate not to inform individuals for having MBL and not to prompt any monitoring [34, 41].

\section{Commentary on CLL-Like MBL}

Based on the above data the following comments can be made. CLL-like MBL is a quite common condition, being at least 100 times more frequent than CLL. Based on the absolute clonal B-cell count, MBL is further divided into low- and high-count MBL. Not all MBL carry the same risk of clinical progression. The absolute clonal B lymphocyte count is the only well-established prognostic factor so far for the detection of the risk for the progression of $\mathrm{MBL}$ into CLL. New data on the biology of MBLs may help to better discriminate the subset of MBLs which are more likely to progress from those cases with no propensity to progression. LC-MBL $(<500 / \mu \mathrm{L}$ clonal B cells $)$ is identified in healthy adults during screening-population studies, while clinical or HC-MBL is usually identified during evaluation of lymphocytosis. Based on the current data, LC-MBL is a condition with no clinical relevance and do not require any monitoring. It appears to represent a physiological process of age-related immune senescence rather than a truly premalignant condition. Finally, HC-MBL closely resembles CLL-Rai0 and research is ongoing to identify factors that could help in discriminating those cases with high risk for progression. Table 3 summarizes the main differences in clinical, cytogenetic, and molecular characteristics between HC-MBL, LC-MBL, CLL-0, and CLL > 0 .

\section{CD5(-) MBL}

Data on the clinical aspects and biological significance of non-CLL-like MBL is limited. Non-CLL-like MBL has generally been subdivided into two major groups: CD5(-) $\mathrm{MBL}$ and atypical CD5(+) MBL. Atypical MBL displays CD5 
TABLE 3: Main clinical, cytogenetic, and molecular features of CLL-0, CLL>0, HC-MBL, and LC-MBL.

\begin{tabular}{|c|c|c|c|c|}
\hline \multirow{2}{*}{ Characteristics } & CLL $>0$ & CLL-0 & HC-MBL & LC-MBL \\
\hline & \multicolumn{4}{|c|}{$\%$} \\
\hline Annual risk of progression & & 5.2 & 1.1 & 0 \\
\hline Del 13q & 50 & $\sim 40$ & $\sim 40$ & $\sim 30$ \\
\hline Trisomy 12 & 16 & $\sim 20$ & $\sim 20$ & $\sim 10$ \\
\hline Del 11q & 18 & $\sim 5$ & $\sim 5$ & 0 \\
\hline Del 17p & 7 & $2-3$ & $0-3$ & 0 \\
\hline Unmutated IGHV genes & $\sim 45$ & $\sim 25$ & $\sim 25$ & $\sim 25$ \\
\hline VH1-69 & $\sim 13$ & $\sim 5$ & $\sim 8$ & $\sim 3$ \\
\hline VH4-59/61 & $<5$ & $\sim 5$ & $<5$ & $\sim 20$ \\
\hline BCR stereotypy & $\sim 5$ & $\sim 20$ & $\sim 20$ & $\sim 30$ \\
\hline NOTCH 1 mutation & $>15$ & 13 & 11 & 0 \\
\hline
\end{tabular}

positivity along with higher expression of CD20 and other immunophenotypic features different from typical CLLlike MBL cells [3-5], resembling the immunophenotype of mantle-cell lymphoma. In most CD5(-) MBL cases, clonal $\mathrm{B}$ cells display either an unclassifiable or a marginal zone lymphoma- (MZL-) like immunophenotype. However we should take into account that although most marginal zone lymphoma clones are CD5(-), occasionally CD5 is positive.

The frequency of non-CLL-like MBL is significantly lower than that of CLL-like MBL, comprising less than $20 \%$ of $\mathrm{MBL}$ cases. In the general population studies the prevalence ranges from less than $1 \%$ to $2 \%$, depending mainly on the sensitivity of the flow cytometry used $[4,5]$. The frequency of non-CLL-like MBLs increases with age. Nieto et al. found a progressively higher frequency of non-CLL-like MBL cases in the general population with increasing age ranging from $0.4 \%$ among subjects aged $40-59$ years to $5.4 \%$ among individuals over 80 years of age with a male predominance [59].

The clinical course of low-count MBL is usually indolent with no evidence of progression to overt lymphoma. A study by Fazi et al., which included only low-count MBL cases, showed that CD5(-) MBL tended to be transient in a significant proportion of cases (3/9) [33]. These results differ from those published in a series of 12 atypical CLL and CD5(-) MBL reevaluated 12 months after the first immunophenotypic analysis [59]. All clones were confirmed and even showed a significant increase in the median concentration of clonal B cells, without however progression to overt lymphoma. Furthermore in the latter study it was shown that a significant proportion of non-CLL-like MBL cases (4/13) showed biclonality.

The biology and clinical significance of clinical non-CLLlike MBL has only recently been investigated. There is only a limited series of patients addressing this issue. Amato et al. reported on 7 cases with CD5(-) non-CLL-like clonal B-cell lymphocytosis with an absolute lymphocyte count ranging from 3,600 to $9,400 / \mu \mathrm{L}[60]$. The clonal population accounted for $95 \%$ to $99 \%$ of B cells. The mean age at diagnosis was 72.6 years. Somatic hypermutations of the IGHV gene were found in 6 of 7 cases with different $\mathrm{VH}$ gene repertoire from that of CLL. Furthermore, cytogenetic aberrations were found in 5 of 6 cases: 2 cases bearing isochromosome 17q that resulted in loss of p53 and 2 other cases that displayed clones with $7 \mathrm{q}$ abnormalities. These latter cases had no evidence of an underlying splenic marginal zone lymphoma. During a follow-up period of 4 to 16 years there was no indication of progression to overt lymphoma. The lymphocytosis was persistent but no progressing.

In 2010 our group described an entity presenting with bone marrow infiltration and blood involvement by CD5(-) lymphocytes of marginal zone origin without any other disease localization, which was named primary bone marrow MZL (PBMMZL) [61]. A total of 23 cases were analyzed; 16 of them presented with lymphocytosis. All patients included in this study had undergone bone marrow evaluation, wholebody CT scan, and gastroscopy. Blood lymphocytes were heterogeneous, consisting mainly of small lymphocytes admixed with medium size lymphocytes with nuclear indentations and monocytoid and villous lymphocytes in various proportions. Blood immunophenotype disclosed a clonal Bcell population with strong expression of CD20 and CD79a and moderate to strong expression of surface light chain; approximately half of the cases also expressed the CD23 and CD11c markers, while all cases were negative for the CD5 antigen. Paraproteinemia was observed in almost half of the cases, mainly of the IgG or IgM type at various levels. Bone marrow was always infiltrated but there was a highly variable degree of infiltration (10-90\%, median 25\%). The findings of the above study disclosed that CD5(-) MBL displays many similarities with marginal zone lymphomas, mainly the splenic form.

In an attempt to further evaluate these results we performed a comparative study of splenic marginal zone lymphoma (SMZL) and CD5(-) MBL, which disclosed that CD5(-) MBL displays similar features with SMZL regarding morphology of lymphomatous cells, bone marrow infiltration pattern, and immunophenotypic findings [62].

Based on this analysis, we soon came up with a difficulty to characterize and stratify cases with clonal B-cell counts more than $5000 / \mu \mathrm{L}$, which cannot be characterized as $\mathrm{MBL}$, since there is not currently any recognized entity to include such cases.

In an effort to further investigate this issue we performed an analysis on 44 cases with CD5(-) clonal B cells [63]. 


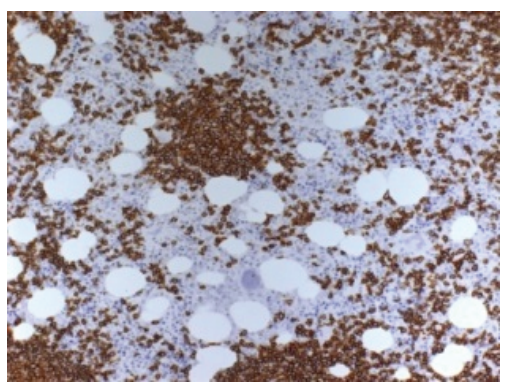

(a) Nodular pattern

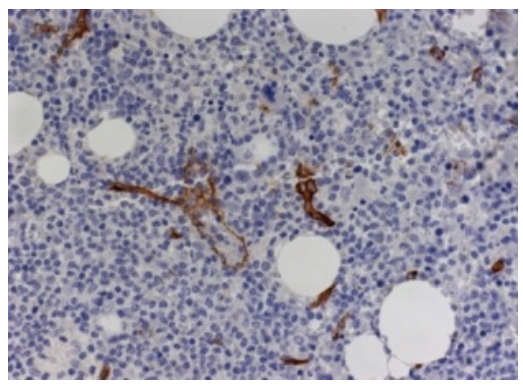

(b) Intrasinusoidal pattern

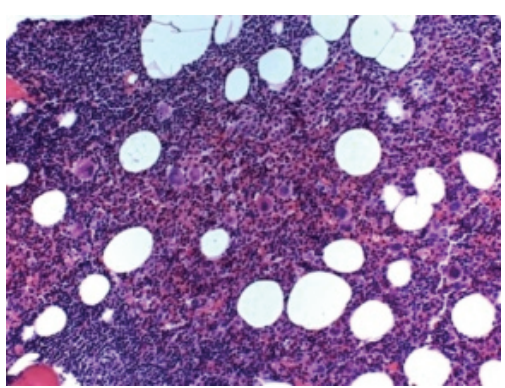

(c) Mixed pattern

FIGURE 1: Different patterns of bone marrow infiltration in CD5(-) MBL cases.

22 of them presented with less than $5000 / \mu \mathrm{L}$ clonal B cells (the median absolute count of clonal B cells was $1123 / \mu \mathrm{L}$ ) and could be formally characterized as MBL, while the other 22 cases presented with more than $5000 / \mu \mathrm{L}$ clonal B cells (median count was $6096 / \mu \mathrm{L}$ ) and could not be classified under a well-recognized entity. In order to describe these cases, we adopted the term "CD5-monoclonal B-cell lymphoproliferation." No difference was noticed between the two groups regarding morphology of lymphomatous cells, immunophenotype, pattern, and extent of bone marrow infiltration. Bone marrow evaluation revealed a variable extent of infiltration (median 25\%, range 5-80\%), while the pattern of infiltration was mixed in the majority of the cases and intrasinusoidal infiltration was evident in one-third of the cases (Figures 1(a), 1(b), and 1(c)). Immunohistochemistry showed a strong expression of CD20 along with negativity for CD5 in all cases, while DBA-44 was positive in approximately half of the cases. Analysis of the IgHV mutation status and of the $\mathrm{VH}$ gene usage was performed in 20 cases. Unmutated $\mathrm{VH}$ genes were noticed in only $25 \%$ of the cases, while the VH4-34*01 was the most commonly used VH gene. Differences were observed only regarding the clinical course of these two subcategories: in cases with $<5000 / \mu \mathrm{L}$ clonal B cells 19/22 (86\%) remained stable after a median follow-up time of 27 months, while 2 presented a gradual increase of ALC, without cytopenias or any other features consistent with a lymphoproliferative disorder. In one case MBL regressed a year later. Among MBL cases with $>5000 / \mu \mathrm{L}$ clonal B cells after a median follow-up of 48 months (range, 7-154), 10 had stable CBC, 9 had a gradual increase of ALC, 3 progressed, and 2 had resolution of lymphocytosis 6 and 24 months after diagnosis, respectively. Two out of the 3 progressing patients developed cytopenias 57 and 79 months after diagnosis, respectively, while 1 patient developed minimal splenomegaly and pancytopenia 130 months later. These 3 patients were treated with rituximab and achieved complete response. This data showed that CD5-MBL displays many similarities with marginal zone lymphomas and that cases with more than $5000 / \mu \mathrm{L}$ clonal B cells may display a more aggressive clinical course than the typical MBL cases, probably representing a distinct entity. Lymphoplasmacytic lymphoma and IgMlike MGUS are two other entities which may overlap with CD5(-) MBL, at least in a proportion of cases presenting with plasmacytic differentiation and paraproteinemia.
Berger et al. used the term leukemic form in an attempt to characterize lymphomas with MZL features, which could not be classified in any of the subcategories of MZL [64]. Our group had used the term primary bone marrow marginal zone lymphoma in order to describe those cases.

A recent collaborative study on a larger series of patients thoroughly evaluated the clinical aspects, biology, and outcome of 102 non-CLL-like clonal B-cell lymphocytosis cases [65]. The median age at presentation was 70 years with a wide range from less than 40 to more than 90 years, with no sex predilection. Absolute lymphocyte counts ranged from 3,000 to $37,100 / \mu \mathrm{L}$. Lymphocyte morphology was characterized by heterogeneity, comprised of small lymphocytes, monocytoidlike admixed with variant proportion of villous lymphocytes and lymphocytes with plasmacytoid features. Paraproteinemia was evident in approximately one-third of the cases. The immunophenotype was consistent with a marginal zone derivation since the clonal B cells displayed strong expression of B-cell markers (CD20), moderate to strong expression of surface Ig, and negativity for CD10, with a Matutes score $<2$. Other markers were positive in a proportion of the cases: CD5 in $18.6 \%$, CD23 in $15.6 \%$, and CD38 in $11.3 \%$. CD79b and FMC-7 were positive in the majority of the cases $(>80 \%)$. CD49d was positive in all 35 studied cases along with low coexpression of CD38. This was the first published study evaluating the bone marrow histopathology and immunohistochemistry of CBL. In most cases a mixed pattern of infiltration was noticed, mainly interstitial along with intrasinusoidal or nodular. Lymphocytes usually were of small size, while there was a wide variation of the percentage of $\mathrm{BM}$ infiltration ranging from less than $10 \%$ to more than $70 \%$, with no correlation between the extent of bone marrow infiltration and the absolute number of circulating clonal B cells. Plasmacytic differentiation was presented in some cases. Immunohistochemistry was characterized by expression of CD20 and CD79a, while DBA44 was positive in approximately one-third of the cases. CD5 and CD23 were positive in one and four cases, respectively, but with no coexpression, while cyclin-D1 was always negative.

Cytogenetic analysis revealed an abnormal karyotype in the majority of the cases $(\sim 70 \%)$, while complex karyotype was found in $23 \%$. The chromosomes most frequently involved included 3,12, 17, and 7. A high incidence (27\%) of aberrations involving chromosome 7 was observed. Del7q 
which is a typical abnormality in splenic marginal zone lymphoma was detected in $12.5 \%$ of MBL cases. Isochromosome $17 \mathrm{q}$ was identified in $16.6 \%$. The majority of CBL cases $(>70 \%)$ carried somatically mutated IGHV genes, with predominance of IGHV4-34 gene. MYD-88 L265P mutation was negative in all of the 45 studied cases. The clinical course varied, with a median follow-up of 5 years; 85 patients remained with isolated lymphocytosis, while 17 cases progressed to an overt lymphoma. Fifteen of them developed splenomegaly, one developed a gastric MALT lymphoma, and one developed diffuse large B-cell lymphoma (DLBCL) of the skin. No difference was found between stable and progressing cases regarding clinical and laboratory characteristics at diagnosis, degree of marrow infiltration, IGHV gene repertoire, and mutational status, while the cytogenetic profiles of the two groups were distinct. Deletions of chromosome $7 \mathrm{q}$ were confined to the stable group and complex karyotypes were more frequent in the progressing one. Based on the above study, CBL is closely related to marginal zone lymphomas and in particular to the splenic form: the presence of villous lymphocytes, lymphocytes with plasmacytoid differentiation, intrasinusoidal pattern of bone marrow infiltration, cytogenetic abnormalities of chromosome 7q34, and development of splenomegaly in a significant proportion of cases. According to this study a new term has been initiated which is clonal $\mathrm{B}$-cell lymphocytosis with marginal zone features (MZ-CBL), in order to include cases with CD5(-) clonal $B$ cells irrespective of the absolute number, which fulfill otherwise all the established criteria for MBL diagnosis and proposed to be included in the WHO classification as a provisional entity.

Further studies are required in order to better characterize this entity, identify the relationship with SMZL, and distinguish the majority of cases of MZ-CBL that will remain clinically stable from those destined to progress. Furthermore, no clear recommendations can be made regarding the staging procedures at diagnosis. CT scanning or ultrasonography to exclude nodal and especially splenic enlargement is mandatory, while routine screening for extranodal lymphomas (e.g., gastroscopy) in the absence of specific symptoms is not generally required. Bone marrow examination is mandatory since it provides additional diagnostic information. Since disease progression can occur, often many years after presentation, MZ-CBL cases require long-term follow-up [65].

\section{Commentary on CD5(-) MBL}

On the basis of the aforementioned data the following comments can be made: CD5(-) MBL displays features consistent with a marginal zone origin. The cutoff value of less than $5000 / \mu \mathrm{L}$ CD5(-) clonal B cells cannot be applied in non-CLL-like MBL, since in contrast to CLL, there is not currently a defined entity to include cases with more than $5000 / \mu \mathrm{L}$ CD5(-) clonal blood B cells. The term MZ-CBL can better describe non-CLL-like cases with clonal B-cell lymphocytosis, irrespective of the absolute number of clonal $\mathrm{B}$ cells, and it may be regarded as a provisional entity, probably under the name of "primary bone marrow marginal zone lymphoma." The majority of $\mathrm{MZ}-\mathrm{CBL}$ present an indolent and stable clinical course. Nevertheless, a proportion of such cases may progress into an overt lymphoma, usually SMZL. Finally, further studies are required in order to better define this entity.

\section{Conflict of Interests}

The authors report that there is no conflict of interests regarding the publication of this paper.

\section{References}

[1] T. Han, H. Ozer, M. Gavigan et al., "Benign monoclonal B cell lymphocytosis. A benign variant of CLL: clinical, immunologic, phenotypic, and cytogenetic studies in 20 patients," Blood, vol. 64, no. 1, pp. 244-252, 1984.

[2] E. Kimby, H. Mellstedt, M. Bjorkholm, and G. Holm, “Clonal cell surface structures related to differentiation, activation and homing in B-cell chronic lymphocytic leukemia and monoclonal lymphocytosis undetermined significance," European Journal of Haematology, vol. 43, no. 5, pp. 452-459, 1989.

[3] W. G. Nieto, J. Almeida, A. Romero et al., "Increased frequency (12\%) of circulating chronic lymphocytic leukemia-like B-cell clones in healthy subjects using a highly sensitive multicolor flow cytometry approach," Blood, vol. 114, no. 1, pp. 33-37, 2009.

[4] A. C. Rawstron, M. J. Green, A. Kuzmicki et al., "Monoclonal B lymphocytes with the characteristics of "indolent" chronic lymphocytic leukemia are present in $3.5 \%$ of adults with normal blood counts," Blood, vol. 100, no. 2, pp. 635-639, 2002.

[5] P. Ghia, G. Prato, C. Scielzo et al., "Monoclonal $\mathrm{CD}^{+}$and $\mathrm{CD}^{-}$ B-lymphocyte expansions are frequent in the peripheral blood of the elderly," Blood, vol. 103, no. 6, pp. 2337-2342, 2004.

[6] L. Scarfò, A. Dagklis, C. Scielzo, C. Fazi, and P. Ghia, "CLL-like monoclonal B-cell lymphocytosis: are we all bound to have it?" Seminars in Cancer Biology, vol. 20, no. 6, pp. 384-390, 2010.

[7] J. Almeida, W. G. Nieto, C. Teodosio et al., "CLL-like Blymphocytes are systematically present at very low numbers in peripheral blood of healthy adults," Leukemia, vol. 25, no. 4, pp. 718-722, 2011.

[8] G. E. Marti, A. C. Rawstron, P. Ghia et al., "Diagnostic criteria for monoclonal B-cell lymphocytosis," British Journal of Haematology, vol. 130, no. 3, pp. 325-332, 2005.

[9] Y. K. Shim, R. F. Vogt, D. Middleton et al., "Prevalence and natural history of monoclonal and polyclonal B-cell lymphocytosis in a residential adult population," Cytometry B-Clinical Cytometry, vol. 72, no. 5, pp. 344-353, 2007.

[10] J. M. Rachel, M. L. Zucker, C. M. Fox et al., "Monoclonal B-cell lymphocytosis in blood donors," British Journal of Haematology, vol. 139, no. 5, pp. 832-836, 2007.

[11] A. C. Rawstron, F. L. Bennett, S. J. M. O’Connor et al., "Monoclonal B-cell lymphocytosis and chronic lymphocytic leukemia," The New England Journal of Medicine, vol. 359, no. 6, pp. 575-583, 2008.

[12] A. Dagklis, C. Fazi, C. Sala et al., "The immunoglobulin gene repertoire of low-count chronic lymphocytic leukemia (CLL)-like monoclonal B lymphocytosis is different from CLL: diagnostic implications for clinical monitoring," Blood, vol. 114, no. 1, pp. 26-32, 2009. 
[13] Y. K. Shim, J. M. Rachel, P. Ghia et al., "Monoclonal Bcell lymphocytosis in healthy blood donors: an unexpectedly common finding," Blood, vol. 123, no. 9, pp. 1319-1326, 2014.

[14] D. M. Matos, S. J. Ismael, C. A. Scrideli, F. M. de Oliveira, E. M. Rego, and R. P. Falcão, "Monoclonal B-cell lymphocytosis in first-degree relatives of patients with sporadic (non-familial) chronic lymphocytic leukaemia," British Journal of Haematology, vol. 147, no. 3, pp. 339-346, 2009.

[15] G. E. Marti, P. Carter, F. Abbasi et al., "B-cell monoclonal lymphocytosis and B-cell abnormalities in the setting of familial B-cell chronic lymphocytic leukemia," Cytometry B: Clinical Cytometry, vol. 52, no. 1, pp. 1-12, 2003.

[16] A. C. Rawstron, M. R. Yuille, J. Fuller et al., "Inherited predisposition to CLL is detectable as subclinical monoclonal Blymphocyte expansion," Blood, vol. 100, no. 7, pp. 2289-2291, 2002.

[17] T. D. Shanafelt, N. E. Kay, G. Jenkins et al., "B-cell count and survival: differentiating chronic lymphocytic leukemia from monoclonal B-cell lymphocytosis based on clinical outcome," Blood, vol. 113, no. 18, pp. 4188-4196, 2009.

[18] D. Rossi, E. Sozzi, A. Puma et al., "The prognosis of clinical monoclonal B cell lymphocytosis differs from prognosis of Rai 0 chronic lymphocytic leukaemia and is recapitulated by biological risk factors," British Journal of Haematology, vol. 146, no. 1, pp. 64-75, 2009.

[19] L. Scarfo, S. Zibellini, A. Tedeschi et al., "Impact of B-cell count and imaging screening in CMBL: any need to revise the current guidelines," Leukemia, vol. 26, no. 7, pp. 1703-1707, 2012.

[20] A. C. Rawstron, T. Shanafelt, M. C. Lanasa et al., "Different biology and clinical outcome according to the absolute numbers of clonal B-cells in monoclonal B-cell lymphocytosis (MBL)," Cytometry Part B: Clinical Cytometry, vol. 78, supplement 1, pp. S19-S23, 2010.

[21] T. D. Shanafelt, P. Ghia, M. C. Lanasa, O. Landgren, and A. C. Rawstron, "Monoclonal B-cell lymphocytosis (MBL): biology, natural history and clinical management," Leukemia, vol. 24, no. 3, pp. 512-520, 2010.

[22] M. C. Lanasa, S. D. Allgood, A. D. Volkheimer et al., "Single-cell analysis reveals oligoclonality among low-count monoclonal Bcell lymphocytosis," Leukemia, vol. 24, no. 1, pp. 133-140, 2010.

[23] A. Henriques, A. Rodríguez-Caballero, I. Criado et al., "Molecular and cytogenetic characterization of expanded B-cell clones from multiclonal versus monoclonal B-cell chronic lymphoproliferative disorders," Haematologica, vol. 99, no. 5, pp. 897-907, 2014.

[24] S. S. Fung, K. L. Hillier, C. S. Leger et al., "Clinical progression and outcome of patients with monoclonal B-cell lymphocytosis," Leukemia and Lymphoma, vol. 48, no. 6, pp. 1087-1091, 2007.

[25] W. Kern, U. Bacher, C. Haferlach et al., "Monoclonal Bcell lymphocytosis is closely related to chronic lymphocytic leukaemia and may be better classified as early-stage CLL," British Journal of Haematology, vol. 157, no. 1, pp. 86-96, 2012.

[26] T. D. Shanafelt, N. E. Kay, K. G. Rabe et al., "Brief report: natural history of individuals with clinically recognized monoclonal Bcell lymphocytosis compared with patients with Rai 0 chronic lymphocytic leukemia," Journal of Clinical Oncology, vol. 27, no. 24, pp. 3959-3963, 2009.

[27] C. S. Mulligan, M. E. Thomas, and S. P. Mulligan, "Monoclonal B-cell lymphocytosis and chronic lymphocytic leukemia," The New England Journal of Medicine, vol. 359, no. 19, pp. 20652066, 2008.
[28] T. D. Shanafelt, N. E. Kay, T. G. Call et al., "MBL or CLL: Which classification best categorizes the clinical course of patients with an absolute lymphocyte count $\geq 5 \times 10^{9} \mathrm{~L}^{-1}$ but a B-cell lymphocyte count $<\mathbf{5} \times 10^{9} \mathrm{~L}^{-1}$ ?" Leukemia Research, vol. 32, no. 9, pp. 1458-1461, 2008.

[29] S. Molica, M. Gentile, F. R. Mauro et al., "An increased number of individuals with clinically recognized monoclonal B-cell lymphocytosis characterizes a recent database of chronic lymphocytic leukemia Rai stage 0," Acta Haematologica, vol. 127, no. 3, pp. 149-151, 2012.

[30] S. Molica, F. R. Mauro, M. Molica, I. D. Giudice, and R. Foà, "Monoclonal B-cell lymphocytosis: a reappraisal of its clinical implications," Leukemia and Lymphoma, vol. 53, no. 9, pp. 1660$1665,2012$.

[31] A. C. Rawstron, "Monoclonal B-cell lymphocytosis," Hematology, pp. 430-439, 2009.

[32] J. Moreira, K. G. Rabe, J. R. Cerhan et al., "Infectious complications among individuals with clinical monoclonal B-cell lymphocytosis (MBL): a cohort study of newly diagnosed cases compared to controls," Leukemia, vol. 27, no. 1, pp. 136-141, 2013.

[33] C. Fazi, L. Scarfò, L. Pecciarini et al., "General population lowcount CLL-like MBL persists over time without clinical progression, although carrying the same cytogenetic abnormalities of CLL," Blood, vol. 118, no. 25, pp. 6618-6625, 2011.

[34] A. Vardi, A. Dagklis, L. Scarfò et al., "Immunogenetics shows that not all MBL are equal: the larger the clone, the more similar to CLL," Blood, vol. 121, no. 22, pp. 4521-4528, 2013.

[35] A. Henriques, A. Rodríguez-Caballero, W. G. Nieto et al., "Combined Patterns of IGHV Repertoire and Cytogenetic/ Molecular Alterations in Monoclonal B Lymphocytosis versus Chronic Lymphocytic Leukemia," PLoS ONE, vol. 8, no. 7, Article ID e67751, 2013.

[36] P. Ghia, G. Prato, S. Stella, C. Scielzo, M. Geuna, and F. Caligaris-Cappio, "Age-dependent accumulation of monoclonal CD4+CD8 +double positive T lymphocytes in the peripheral blood of the elderly," British Journal of Haematology, vol. 139, no. 5, pp. 780-790, 2007.

[37] A. W. Hauswirth, J. Almeida, W. G. Nieto et al., "Monoclonal B-cell lymphocytosis (MBL) with normal lymphocyte counts is associated with decreased numbers of normal circulating B-cell subsets," The American Journal of Hematology, vol. 87, no. 7, pp. 721-724, 2012.

[38] U. Randen, A. M. Tierens, G. E. Tjonnfjord, and J. Delabie, "Bone Marrow histology in monoclonal b-cell lymphocytosis shows various b-cell infiltration patterns," The American Journal of Clinical Pathology, vol. 139, no. 3, pp. 390-395, 2013.

[39] M. C. Lanasa, S. D. Allgood, S. L. Slager et al., "Immunophenotypic and gene expression analysis of monoclonal B-cell lymphocytosis shows biologic characteristics associated with good prognosis CLL," Leukemia, vol. 25, no. 9, pp. 1459-1466, 2011.

[40] S. Quijano, A. López, A. Rasillo et al., "Impact of trisomy 12 , del(13q), del(17p), and $\operatorname{del}(11 q)$ on the immunophenotype, DNA ploidy status, and proliferative rate of leukemic Bcells in chronic lymphocytic leukemia," Cytometry B-Clinical Cytometry, vol. 74, no. 3, pp. 139-149, 2008.

[41] P. Ghia and F. Caligaris-Cappio, "Monoclonal B-cell lymphocytosis: right track or red herring?" Blood, vol. 119, no. 19, pp. 4358-4362, 2012.

[42] P. Ghia, F. Melchers, and A. G. Rolink, "Age-dependent changes in B lymphocyte development in man and mouse," Experimental Gerontology, vol. 35, no. 2, pp. 159-165, 2000. 
[43] A. Agathangelidis, N. Darzentas, A. Hadzidimitriou et al., "Stereotyped B-cell receptors in one-third of chronic lymphocytic leukemia: a molecular classification with implications for targeted therapies," Blood, vol. 119, no. 19, pp. 4467-4475, 2012.

[44] D. Casabonne, J. Almeida, W. G. Nieto et al., "Common infectious agents and monoclonal B-cell lymphocytosis: a crosssectional epidemiological study among healthy adults," PLoS ONE, vol. 7, no. 12, Article ID e52808, 2012.

[45] L. A. Anderson, O. Landgren, and E. A. Engels, "Common community acquired infections and subsequent risk of chronic lymphocytic leukaemia," British Journal of Haematology, vol. 147, no. 4, pp. 444-449, 2009.

[46] G. Fabbri, S. Rasi, D. Rossi et al., "Analysis of the chronic lymphocytic leukemia coding genome: role of NOTCH1 mutational activation," Journal of Experimental Medicine, vol. 208, no. 7, pp. 1389-1401, 2011.

[47] D. Rossi, A. Bruscaggin, V. Spina et al., "Mutations of the SF3B1 splicing factor in chronic lymphocytic leukemia: association with progression and fludarabine-refractoriness," Blood, vol. 118, no. 26, pp. 6904-6908, 2011.

[48] D. Rossi, M. Fangazio, S. Rasi et al., "Disruption of BIRC3 associates with fludarabine chemorefractoriness in TP53 wildtype chronic lymphocytic leukemia," Blood, vol. 119, no. 12, pp. 2854-2862, 2012.

[49] M. Greco, D. Capello, A. Bruscaggin et al., "Analysis of SF3B1 mutations in monoclonal B-cell lymphocytosis," Hematological Oncology, vol. 31, no. 1, pp. 54-55, 2013.

[50] R. Foà, I. del Giudice, A. Guarini, D. Rossi, and G. Gaidano, "Clinical implications of the molecular genetics of chronic lymphocytic leukemia," Haematologica, vol. 98, no. 5, pp. 675685, 2013 .

[51] M. Lionetti, S. Fabris, G. Cutrona et al., "High-throughput sequencing for the identification of NOTCH1 mutations in early stage chronic lymphocytic leukaemia: biological and clinical implications," British Journal of Haematology, vol. 165, no. 5, pp. 629-639, 2014.

[52] G. A. Calin, M. Ferracin, A. Cimmino et al., "A microRNA signature associated with prognosis and progression in chronic lymphocytic leukemia," The New England Journal of Medicine, vol. 353, no. 17, pp. 1793-1801, 2005.

[53] A. Ferrajoli, T. D. Shanafelt, C. I. Masayoshi Shimizu et al., "Prognostic value of miR-155 in individuals with monoclonal B-cell lymphocytosis and patients with B chronic lymphocytic leukemia," Blood, vol. 122, pp. 1891-1899, 2013.

[54] A. Henriques, A. Rodriguez-Caballero, I. Criado et al., "Molecular and cytogenetic characterization of expanded B-cell clones from multiclonal versus monoclonal B-cell chronic lymphoproliferative disorders," Haematologica, vol. 99, no. 5, pp. 897-907, 2014.

[55] G. A. Pangalis, V. A. Boussiotis, and C. Kittas, "Malignant disorders of small lymphocytes: small lymphocytic lymphoma, lymphoplasmacytic lymphoma, and chronic lymphocytic leukemia: their clinical and laboratory relationship," The American Journal of Clinical Pathology, vol. 99, no. 4, pp. 402-408, 1993.

[56] M. Stetler-Stevenson, "Monoclonal B-cell lymphocytosis in donors," Blood, vol. 123, pp. 1281-1282, 2014.

[57] J. J. Castillo, S. Dalia, and S. K. Pascual, "Association between red blood cell transfusions and development of non-Hodgkin lymphoma: a meta-analysis of observational studies," Blood, vol. 116, no. 16, pp. 2897-2907, 2010.

[58] N. M. Hardy, C. Grady, R. Pentz et al., "Bioethical considerations of monoclonal B-cell lymphocytosis: donor transfer after haematopoietic stem cell transplantation," British Journal of Haematology, vol. 139, no. 5, pp. 824-831, 2007.

[59] W. G. Nieto, C. Teodosio, A. López et al., "Primary Health Care Group of Salamanca for the Study of MBL: non- CLLlike monoclonal B-cell lymphocytosis in the general population: prevalence and phenotypic/genetic characteristics," Cytometry Part B: Clinical Cytometry, vol. 78, supplement 1, pp. S24-S34, 2010.

[60] D. Amato, D. G. Oscier, Z. Davis et al., "Cytogenetic aberrations and immunoglobulin $\mathrm{VH}$ gene mutations in clinically benign CD5- monoclonal B-cell lymphocytosis," The American Journal of Clinical Pathology, vol. 128, no. 2, pp. 333-338, 2007.

[61] C. Kalpadakis, G. A. Pangalis, S. Sachanas et al., "Primary bone marrow marginal zone lymphoma (PBMMZL): a new disease entity?" Haematologica, vol. 95, no. 2, p. 109, 2010.

[62] C. Kalpadakis, G. Pangalis, S. Sachanas et al., "Comparative study of splenic marginal zone lymphoma (SMZL) and primary bone marrow MZL (PBMMZL)," Haematologica, vol. 96, no. 2, p. p392, 2011.

[63] C. Kalpadakis, G. A. Pangalis, T. P. Vassilakopoulos et al., "CD5monoclonal B-cell lymphoproliferation (MBL): clinical characteristics and outcome," Haematologica, vol. 97, no. s1, p. p86, 2012.

[64] F. Berger, P. Felman, C. Thieblemont et al., "Non-MALT marginal zone B-cell lymphomas: a description of clinical presentation and outcome in 124 patients," Blood, vol. 95, no. 6, pp. 1950-1956, 2000.

[65] A. Xochelli, C. Kalpadakis, A. Gardiner et al., "Clonal B-cell lymphocytosis exhibiting immunophenotypic features consistent with a marginal-zone origin: is this a distinct entity?" Blood, vol. 123, no. 8, pp. 1199-1206, 2014. 


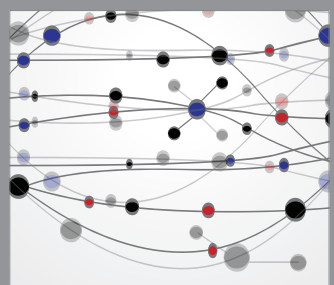

The Scientific World Journal
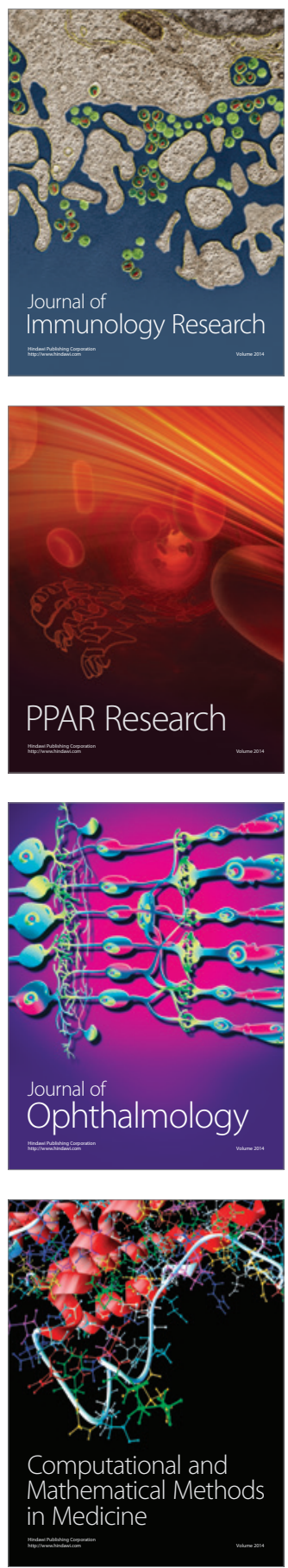

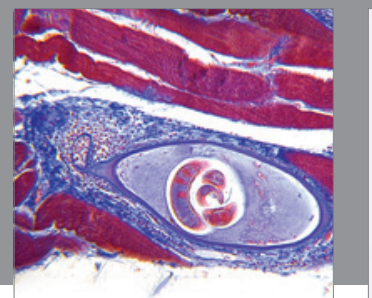

Gastroenterology

Research and Practice
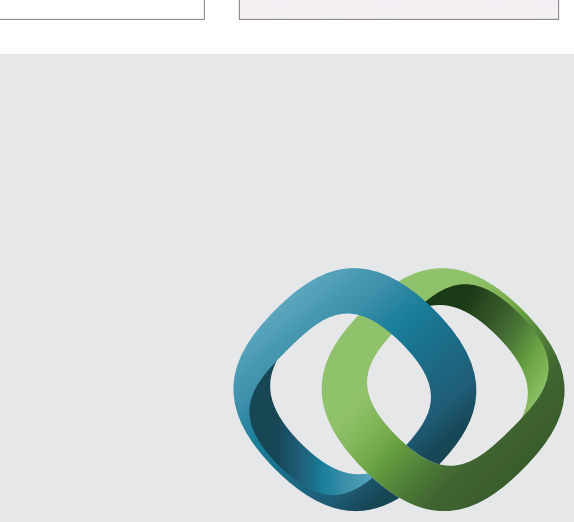

\section{Hindawi}

Submit your manuscripts at

http://www.hindawi.com
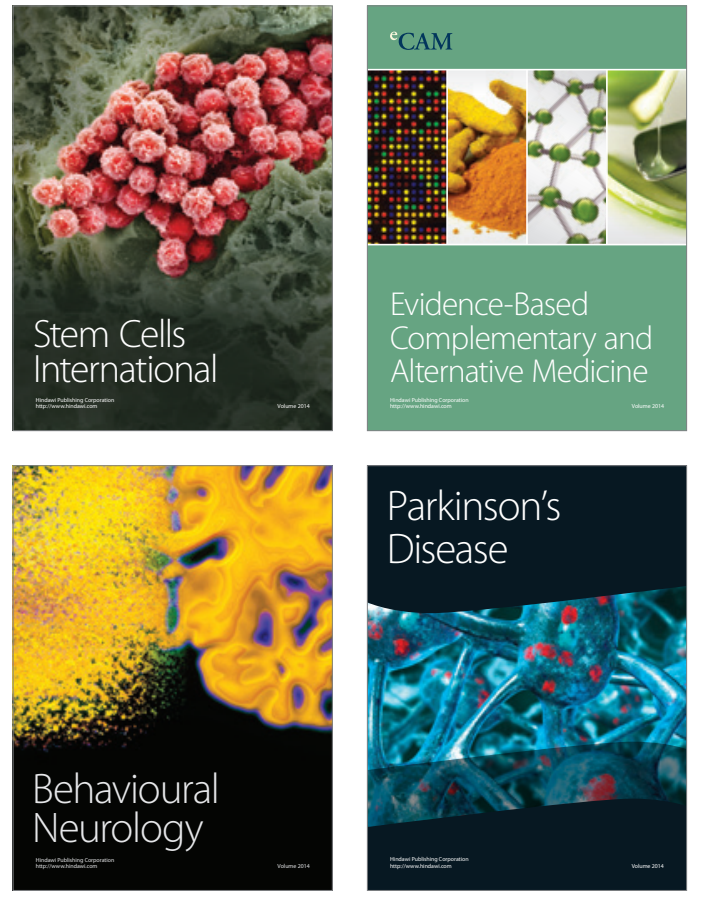
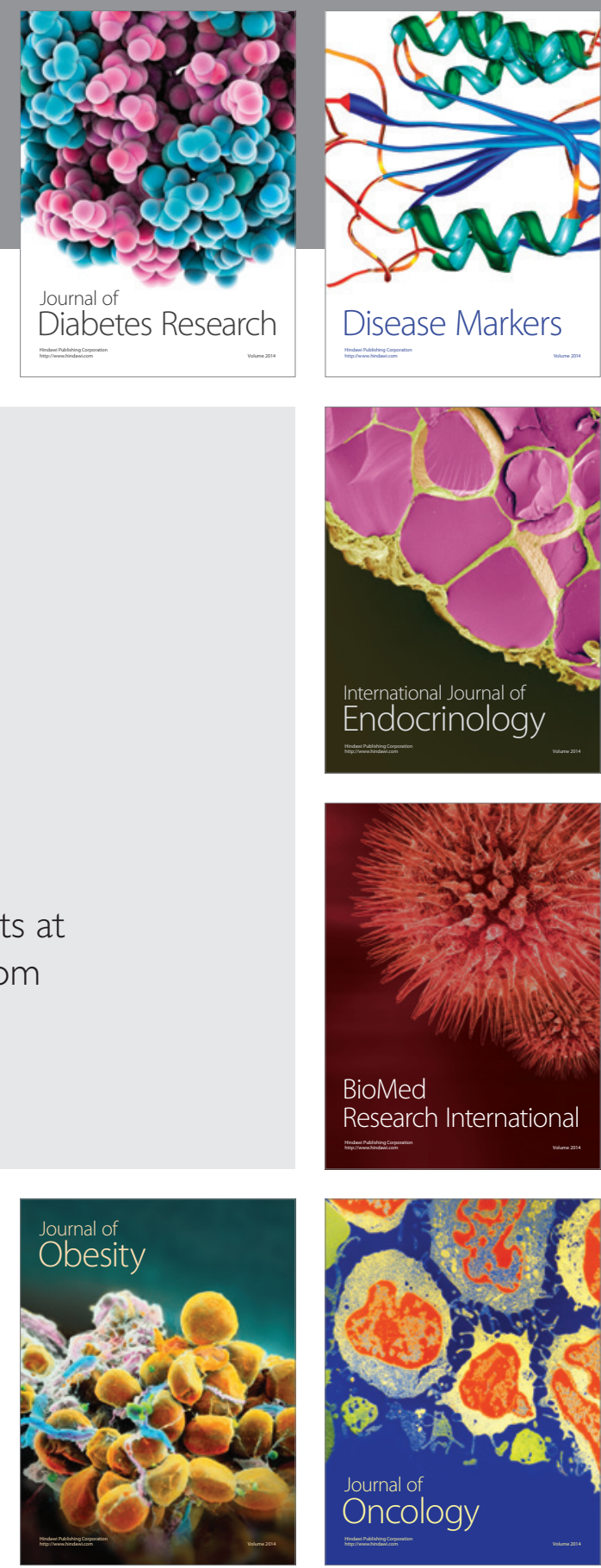

Disease Markers
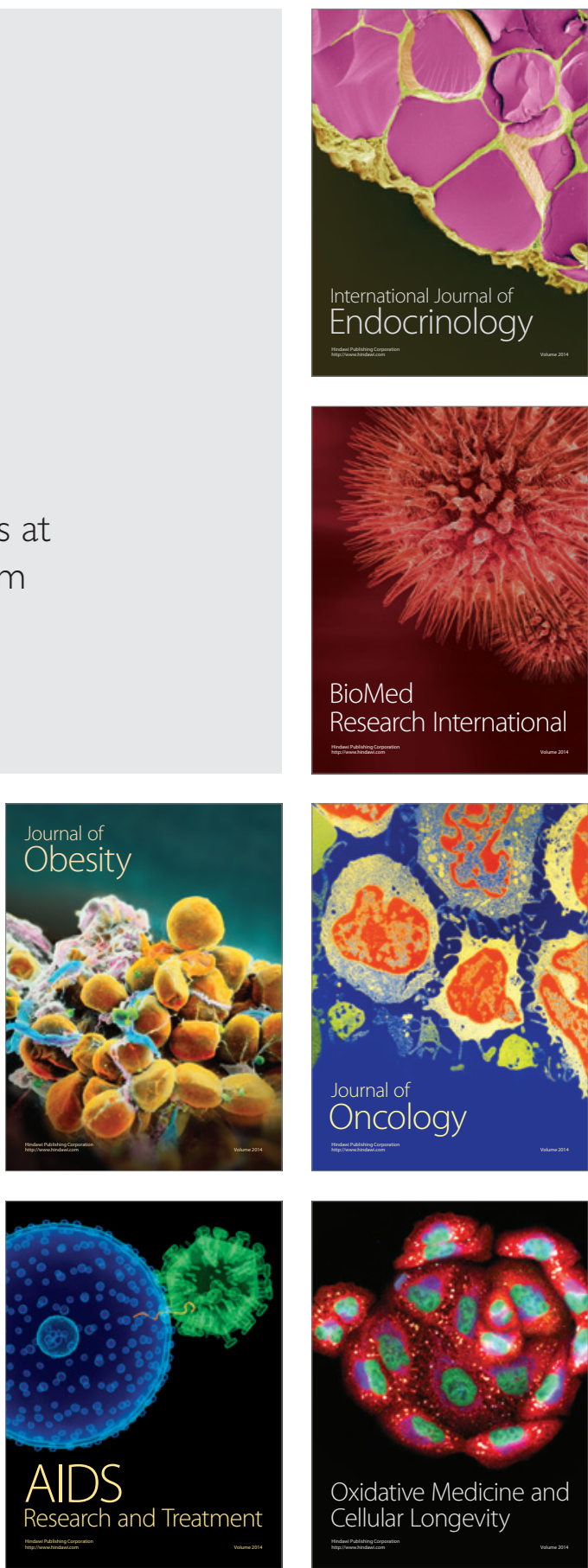